\title{
SUBSTRATOS E TEMPERATURAS PARA O TESTE DE GERMINAÇÃO DE SEMENTES DE Chorisia glaziovii (O. Kuntze)
}

\author{
Roberta Sales Guedes ${ }^{1}$, Edna Ursulino Alves ${ }^{2}$
}

(recebido: 11 de maio de 2010; aceito: 30 de junho de 2011)

RESUMO: Chorisia glaziovii O. Kuntze é uma espécie nativa do Nordeste brasileiro, pertencente à família Bombacaceae que apresenta usos diversificados na medicina popular, na recomposição de áreas degradadas e na indústria de estofados. Com este trabalho, objetivou-se indicar substratos e temperaturas adequados para condução do teste de germinação das sementes de $C$. glaziovii. O experimento foi realizado no Laboratório de Análise de Sementes (CCA - UFPB), Areia - PB, em delineamento inteiramente ao acaso, com os tratamentos distribuídos em esquema fatorial $4 \times 4$ (temperaturas $25,30,35$ e $20-30^{\circ} \mathrm{C}$ e substratos papel toalha, sobre papel mata-borrão, entre areia e entre vermiculita). Foram analisadas as seguintes características: porcentagem, primeira contagem e índice de velocidade de germinação, e comprimento de plântulas. A temperatura de $35^{\circ} \mathrm{C}$ mostrou-se inadequada para a condução dos testes de germinação e vigor de sementes de C. glaziovii, independentemente do substrato utilizado. Recomendam-se, para a condução dos testes de germinação e vigor das sementes de $C$. glaziovii, os substratos entre areia ou papel toalha, nas temperaturas de 25 e $20-30^{\circ} \mathrm{C}$.

Palavras-chave: Barriguda, sementes florestais, vigor, análise de sementes.

\section{SUBSTRATES AND TEMPERATURES FOR THE GERMINATION TEST OF Chorisia glaziovii (O. Kuntze) SEEDS}

\begin{abstract}
The species Chorisia glaziovii O. Kuntze is native to the northeast of Brazil, belongs to Bombacaceae family and has diversified uses in folk medicine, recovery of degraded areas and upholstery industry. The present work was realizated with the objective to determine the substrate type and temperature for conduction of germination tests with C. glaziovii seeds. The experiment was carried out in the Laboratory of Analysis of Seeds (CCA - UFPB), Areia City, Northeast of Brazil, in design completely randomized with the treatments distributed in outline factorial $4 \times 4$ (temperatures of $25,30,35$ and $20-30^{\circ} \mathrm{C}$ and substrate towel paper, among blotting paper, between sand and between vermiculite). The following parameters were analyzed: germination percentage, first count germination, germination speed index, and length of seedlings. The temperature of $35^{\circ} \mathrm{C}$ was shown inadequate for conduction of germination and vigor tests of seeds of C. glaziovii, independently of the used substrates. It is recommended for conduction of the germination and vigor tests of the seeds of C. glaziovii the substrate between sand or towel paper, in the temperatures of 25 and $20-30^{\circ} \mathrm{C}$.
\end{abstract}

Key words: Barriguda, forest seeds, vigor, seed analysis.

\section{INTRODUÇÃO}

A Chorisia glaziovii O. Kuntze é uma espécie florestal, nativa do Nordeste Brasileiro e presente na caatinga hipoxerófila da família Bombacaceae. A árvore é popularmente denominada de barriguda, barriguda de espinho, paineira-branca, barriguda-do-pantanal, árvore-da-seda, árvore-da-lã (LORENZI, 2002). Árvore ornamental de tronco bojudo, com floração branca muito vistosa e que ocorre entre setembro e outubro, período no qual perde totalmente a folhagem, dando lugar a exuberante florescimento.

Sementes revestidas por fibra (lã), utilizada nas indústrias de estofados, no enchimento de travesseiros e colchões e revestimentos em geral. Excelente para plantios heterogêneos em recomposição de áreas degradadas, em razão do seu rápido crescimento (LORENZI, 2002). Seus frutos são apreciados por periquitos e maritacas que consomem a semente e a casca dos frutos, mesmo quando imaturos. Há registros de uso da espécie na medicina popular para doenças do coração e pressão alta e as partes utilizadas são as entrecascas e as flores (LUCENA et al., 2008).

As sementes constituem a via de propagação mais empregada na implantação de plantios, sendo de fundamental interesse o estudo de vários fatores que interferem na propagação, principalmente a germinação e o vigor, que influenciam de forma direta na distribuição das espécies.

\footnotetext{
${ }^{1}$ Bióloga, Doutoranda em Agronomia (Produção e Tecnologia de Sementes) - Departamento de Fitotecnia e Ciências Ambientais - Centro de Ciências Agrárias - Universidade Federal da Paraíba/UFPB - 58397-000 - Areia, PB - roberta_biologa09@yahoo.com.br

${ }^{2}$ Agrônoma, Professora Dra. em Agronomia (Produção e Tecnologia de Sementes) - Departamento de Fitotecnia e Ciências Ambientais - Centro de Ciências Agrárias - Universidade Federal da Paraíba/UFPB - 58397-000 - Areia, PB - ednaursulino@cca.ufpb.br
}

Cerne, Lavras, v. 17, n. 4, p. 525-531, out./dez. 2011 
Conforme Passos et al. (2008), para se determinar o nível de qualidade das sementes, um dos meios utilizados é o teste de germinação; e para a sua condução há componentes básicos que devem ser avaliados, como a temperatura e o substrato (STOCKMAN et al., 2007).

Como a resposta fisiológica das sementes é variável em temperaturas e substratos diferentes, é recomendável que se estude a influência desses componentes na germinação de cada espécie de interesse, fornecendo subsídios para a análise dessas sementes (GUEDES et al., 2009). A escolha do tipo de substrato deve ser feita em função das exigências da semente, especialmente em relação ao seu tamanho e formato (BEZERRA et al., 2002). Setubal e Afonso Neto (2000) citam que o substrato pode ocasionar a nulidade ou irregularidade de germinação, má formação de plantas e o aparecimento de sintomas de deficiência ou excesso de alguns nutrientes.

Sementes de muitas espécies têm os substratos para germinação já especificados, tais como: Adenanthera pavonina L. (SOUZA et al., 2007), Tabebuia chrysotricha (Mart. ex. D.C.) (MARTINS et al., 2008b) e Plantago tomentosa Lam. (DOUSSEAU et al., 2008) - areia; Peltophorum dubium (Sprengel) Taubert (OLIVEIRA et al., 2008) e de Cereus jamacaru DC. (GUEDES et al., 2009) - papel toalha; Eucalyptus dunnii Maiden (CETNARSKI FILHO; CARVALHO, 2009) - areia ou papel toalha; Amburana cearensis (Allemão) A.C. Smith (GUEDES et al., 2010) - areia e vermiculita. Archontophoenix cunninghamii $\mathrm{H}$. Wendl. \& Drude (PIVETTA et al., 2008) vermiculita.

A resposta da germinação em relação à temperatura depende da espécie, variedade, região de origem e tempo de armazenamento, porém, seu efeito na germinação pode ser expresso em temperaturas mínimas, ótimas e máximas, nas quais a germinação pode ocorrer (CETNARSKI FILHO; CARVALHO, 2009). Dessa forma, verificase que as diferentes espécies têm uma temperatura considerada ótima para germinação, na qual a semente expressa seu potencial máximo de germinação no menor espaço de tempo. De acordo com Andrade et al. (2006), a temperatura influencia na porcentagem final e a velocidade da germinação, afetando tanto a absorção de água pela semente quanto às reações bioquímicas que regulam o metabolismo envolvido nesse processo.

A temperatura ótima para a germinação das sementes varia de espécie para espécie e, dessa forma a temperatura ótima para sementes de Phoenix roebelenii
O'Brien (IOSSI et al., 2003), Cecropia glaziovi L. (GODOI; TAKAKI, 2005), Peltophorum dubium (Sprengel) Taubert (OLIVEIRA et al., 2008) e Cereus jamacaru DC. (GUEDES et al., 2009) é a de $30^{\circ} \mathrm{C}$; Dalbergia nigra (Vell.) Fr. All. - 20-30 ${ }^{\circ} \mathrm{C}$ - (ANDRADE et al., 2006); Melocactus bahiensis Britton \& Rose $25^{\circ} \mathrm{C}$ - (LONE et al., 2007); Tabebuia serratifolia (Vahl) Nicholson - entre 25 e $35^{\circ} \mathrm{C}$ - (MACHADO et al., 2002); Archontophoenix cunninghamii $\mathrm{H}$. Wendl. \& Drude -25 e $30^{\circ} \mathrm{C}$ - (PIVETTA et al., 2008); Plantago tomentosa Lam. - 15 e $20^{\circ} \mathrm{C}$ (constante) e $15-25^{\circ} \mathrm{C}$ (alternada) (DOUSSEAU et al., 2008); Amburana cearensis (All.) A.C. Smith $-35^{\circ} \mathrm{C}$ (GUEDES et al., 2010).

Pela falta de informações sobre a germinação das sementes da espécie Chorisia glaziovii, este trabalho tem por objetivo indicar substratos e temperaturas adequados para a condução do teste de germinação da mesma.

\section{MATERIAL E MÉTODOS}

O experimento foi conduzido no Laboratório de Análise de Sementes (LAS), do Centro de Ciências Agrárias, da Universidade Federal da Paraíba, (CCA UFPB), Areia - PB, no período de janeiro a fevereiro de 2010. Os frutos de Chorisia glaziovii foram coletados diretamente de cinco árvores matrizes, e provenientes do Sítio Bosque, município de Campina Grande - PB. Após a coleta, os frutos foram levados ao LAS, onde as sementes foram beneficiadas manualmente e mantidas em laboratório, à sombra, para a secagem natural por cinco dias. Em seguida, foram realizadas as seguintes avaliações:

\subsection{Teste de germinação (substratos e temperaturas)}

Para o teste de germinação foram utilizadas quatro repetições de 25 sementes, sendo instalados nos substratos: papel toalha, organizado na forma de rolo, sobre papel mata-borrão e, entre os substratos vermiculita e areia. Os substratos vermiculita e areia foram umedecidos com água destilada a $60 \%$ de sua capacidade de retenção de água e as sementes foram semeadas a uma profundidade de dois centímetros em bandejas plásticas com dimensões de 0,40 x $0,40 \times 0,11 \mathrm{~m}$.

No substrato papel toalha, as sementes foram distribuídas sobre duas folhas, cobertas com uma terceira e organizadas em forma de rolo, sendo que o mesmo foi umedecido com água destilada no volume $(\mathrm{mL})$, equivalente a 3,0 vezes o peso do substrato, sem adição posterior de água. Os rolos foram acondicionados em

Cerne, Lavras, v. 17, n. 4, p. 525-531, out./dez. 2011 
sacos de plástico, transparente, de 0,04 mm de espessura, com a finalidade de evitar a perda de água por evaporação. No substrato papel mata borrão, as sementes foram distribuídas sobre o papel e postas para germinar em caixas plásticas transparentes do tipo gerbox com dimensões de 11 x 11 x $3 \mathrm{~cm}$ e o umedecimento seguiu o mesmo padrão do papel toalha.

O teste de germinação foi conduzido em germinador tipo Biochemical Oxigen Demand (B.O.D.), regulado para os regimes de temperatura constante de 25,30 e $35^{\circ} \mathrm{C}$ e alternada de $20-30^{\circ} \mathrm{C}$, com fotoperíodo de oito horas, utilizando lâmpadas fluorescentes tipo luz do dia (4 x $20 \mathrm{~W})$.

\subsection{Avaliações}

\subsubsection{Porcentagem final de germinação}

As avaliações foram efetuadas diariamente após a instalação do teste, por um período de 12 dias, quando o experimento foi encerrado. As contagens foram realizadas, considerando-se como sementes germinadas aquelas que emitiram a raiz primária e a parte aérea (plântulas normais) e os resultados expressos em porcentagem.

\subsubsection{Primeira contagem de geminação}

Foi conduzida conjuntamente com o de germinação, onde se computou o número de sementes germinadas no quinto dia, sendo os dados expressos em percentagem.

\subsection{3 Índice de velocidade de germinação (IVG)}

Foi avaliado conjuntamente com o teste de germinação onde foram realizadas contagens diárias, do 5ำ até o $12^{\circ}$ dia após a semeadura, das sementes germinadas e, o índice de velocidade de germinação, foi calculado empregando-se a fórmula proposta por Maguire (1962), onde:

$$
I V G=\frac{G_{1}}{N}+\frac{G_{2}}{N_{2}}+\ldots+\frac{G_{n}}{N_{n}}
$$

sendo:

$G_{1}, G_{2}$ e $G_{n}=$ número de plântulas normais computadas na primeira, na segunda e na última contagem;

$N_{1}, N_{2}$ e $N_{n}=$ número de dias da semeadura à primeira, segunda e última contagem.

\subsubsection{Comprimento de plântulas}

Após a contagem final do teste de germinação, as plântulas normais de cada tratamento e repetição foram medidas (raiz e parte aérea), com auxílio de uma régua graduada em centímetros, sendo os resultados expressos em cm/plântula.

\subsection{Procedimento estatístico}

A análise de variância do experimento foi realizada segundo o delineamento experimental inteiramente ao acaso, com os tratamentos distribuídos em esquema fatorial $4 \times 4$ (temperaturas e substratos), com quatro repetições de 25 sementes cada. Os dados foram submetidos à análise de variância e as médias comparadas pelo teste de ScottKnott, a 5\% de probabilidade.

\section{RESULTADOS E DISCUSSÃO}

Houve interação significativa entre substrato e temperatura para todas as características avaliadas no processo germinativo das sementes de Chorisia glaziovii. Entretanto, em todas essas características estudadas, os efeitos isolados foram mais evidenciados. Os resultados referentes à porcentagem final de germinação (Tabela 1), computados no $12^{\circ}$ dia após a semeadura, revelaram interação entre a temperatura constante de $25^{\circ} \mathrm{C}$ e o substrato areia, proporcionando o máximo desempenho germinativo dessas sementes.

Tabela 1 - Germinação de sementes de Chorisia glaziovii (O) Kuntze) submetidas a diferentes substratos e temperaturas.

Table 1 - Seeds germination (\%) of Chorisia glaziovii (O. Kuntze) subjected to different substrates and temperatures.

\begin{tabular}{lcccc}
\hline \multirow{2}{*}{ Substratos } & \multicolumn{4}{c}{ Temperaturas $\left({ }^{\circ} \mathrm{C}\right)$} \\
\cline { 2 - 5 } & 25 & 30 & 35 & $20-30$ \\
\hline Areia & $86 \mathrm{aA}$ & $71 \mathrm{aC}$ & $10 \mathrm{aD}$ & $78 \mathrm{aB}$ \\
Vermiculita & $74 \mathrm{cA}$ & $59 \mathrm{cC}$ & $1 \mathrm{cD}$ & $71 \mathrm{cB}$ \\
Sobre Papel & $65 \mathrm{dA}$ & $46 \mathrm{dC}$ & $0 \mathrm{cD}$ & $58 \mathrm{~dB}$ \\
Papel Toalha & $80 \mathrm{bA}$ & $67 \mathrm{bC}$ & $5 \mathrm{bD}$ & $74 \mathrm{bB}$ \\
\hline
\end{tabular}

Médias seguidas de mesma letra minúscula na coluna e maiúscula na linha não diferem a 5\% de probabilidade pelo teste de Scott-Knott.

Considerando-se os fatores isolados, constatou-se que a temperatura constante de $25^{\circ} \mathrm{C}$ foi responsável pelos maiores percentuais de germinação, em todos os substratos avaliados, seguido da temperatura alternada de $20-30^{\circ} \mathrm{C}$, independente do substrato. Além da temperatura de $30^{\circ} \mathrm{C}$, as sementes de $C$. glaziovii têm sua germinação afetada negativamente pelas temperaturas mais elevadas, como é o caso da temperatura de $35^{\circ} \mathrm{C}$, em que o máximo de germinação atingido foi de $10 \%$ no substrato de areia.

Cerne, Lavras, v. 17, n. 4, p. 525-531, out./dez. 2011 
Esses resultados corroboram a afirmação de que o efeito da temperatura é variável com a espécie e que está relacionado com o adequado desenvolvimento da planta, influenciando na absorção de água pela semente e nas reações bioquímicas que regulam o processo de germinação e crescimento (BEWLEY; BLACK, 1994).

Embora para a maioria das espécies, a temperatura mais favorável para a germinação oscile entre 26,5 e $35^{\circ} \mathrm{C}$ (LOPES et al., 2005), os resultados aqui apresentados sugerem que, para a germinação de sementes de $C$. glaziovii, deve-se utilizar, preferencialmente, temperatura constante de $25^{\circ} \mathrm{C}$ ou alternada de $20-30^{\circ} \mathrm{C}$, constituindose assim, em temperaturas ótimas, nas quais a mais alta taxa de germinação é obtida em menor intervalo de tempo (CARVALHO; NAKAGAWA, 2000). A exigência por temperaturas alternadas, bem como temperaturas mais baixas devem estar relacionadas às condições ecofisiológicas da espécie, a qual é encontrada em área de transição entre a Mata Atlântica e a Caatinga, cujas temperaturas não são demasiadamente elevadas, especialmente no período em que as sementes estariam germinando (período chuvoso).

Para algumas espécies florestais, essa definição de temperatura ideal pra germinação já foi estabelecida com em Dalbergia nigra (Vell.) Fr. All. ex Benth. - 25 e $20-30^{\circ} \mathrm{C}$ (ANDRADE et al., 2006); Stryphnodendron adstringens (Mart.) Coville $-25,30,35^{\circ} \mathrm{C}$ ou $20-30^{\circ} \mathrm{C}$ (MARTINS et al., 2008a); Cereus jamacaru DC. - $30^{\circ} \mathrm{C}$ (GUEDES et al., 2009); Amburana cearensis (Allemão) A.C. Smith $-35^{\circ} \mathrm{C}$ (GUEDES et al., 2010).

Quanto aos substratos, verifica-se que o substrato sobre papel mata-borrão não se mostrou adequado para promover um porcentual de germinação elevado, possivelmente por esse substrato oferecer menor superfície de contato à semente que os demais substratos, dificultando a embebição de água. Enquanto isso, o substrato areia se destaca com os maiores porcentuais de germinação, independente da temperatura estudada, seguido do papel toalha e, por último, a vermiculita.

Nos testes de germinação, a área de contato do substrato umedecido com a semente é importante e pode ser crítica, tanto para a germinação total, como também para a velocidade de germinação (PETERSON; COOPER, 1979). De acordo com Carneiro e Guedes (1992), quanto maior o contato das sementes com o substrato, menor o tempo necessário para que a germinação total seja alcançada. Tendo em vista o tegumento liso e a forma arredondada das sementes de C. glaziovii, no substrato sobre papel de filtro, a pequena área de contato das sementes com o substrato pode ter sido um dos responsáveis pela redução da germinação das sementes.

Esse tipo de substrato (papel de filtro) favoreceu, ainda, o desenvolvimento de microrganismos, concordando com a observação feita por Figliolia et al. (1993), que menciona esse substrato como inadequado pelo fato de comprometer a capacidade de germinação das sementes, em razão do desenvolvimento de fungos em grande quantidade. Possivelmente, a areia possibilitou melhor distribuição e manutenção da umidade no substrato.

Na Tabela 2, estão contidos os dados referentes ao vigor determinado pela primeira contagem de germinação de sementes de C. glaziovii, computados no quinto dia após a semeadura. Verificou-se que houve interação significativa entre o substrato areia e a temperatura de $25^{\circ} \mathrm{C}$. Analisando-se os fatores isolados observou-se que quando as sementes foram postas para germinar no substrato sobre papel mata-borrão, registraram-se os mais baixos porcentuais de germinação, em todas as temperaturas testadas; enquanto que o substrato areia se destaca por proporcionar um bom desenvolvimento das plântulas, especialmente nas temperaturas de $20-30^{\circ} \mathrm{C}$ e $25^{\circ} \mathrm{C}$.

Tabela 2 - Primeira contagem de germinação (\%) de sementes de Chorisia glaziovii (O. Kuntze) submetidas a diferentes substratos e temperaturas.

Table 2-Seeds first germination count (\%) of Chorisia glaziovii (O. Kuntze) subjected to different substrates and temperatures.

\begin{tabular}{lcccc}
\hline \multirow{2}{*}{ Substratos } & \multicolumn{4}{c}{ Temperaturas $\left({ }^{\circ} \mathrm{C}\right)$} \\
\cline { 2 - 5 } & 25 & 30 & 35 & $20-30$ \\
\hline Areia & $54 \mathrm{aA}$ & $32 \mathrm{aC}$ & $0 \mathrm{aD}$ & $37 \mathrm{bB}$ \\
Vermiculita & $46 \mathrm{cA}$ & $18 \mathrm{cC}$ & $0 \mathrm{aD}$ & $41 \mathrm{aB}$ \\
Sobre Papel & $36 \mathrm{dA}$ & $13 \mathrm{dC}$ & $0 \mathrm{aD}$ & $31 \mathrm{cB}$ \\
Papel Toalha & $49 \mathrm{bA}$ & $26 \mathrm{bC}$ & $0 \mathrm{aD}$ & $30 \mathrm{cB}$ \\
\hline
\end{tabular}

Médias seguidas de mesma letra minúscula na coluna e maiúscula na linha não diferem a 5\% de probabilidade pelo teste de Scott-Knott.

Considerando agora a temperatura como fator isolado, constatou-se que os maiores percentuais de germinação na primeira contagem ocorreram na temperatura de $25^{\circ} \mathrm{C}$, em todos os substratos, seguidos da temperatura de $20-30^{\circ} \mathrm{C}$, que se destacou pelas médias superiores à da temperatura de $30^{\circ} \mathrm{C}$, expressando, dessa forma, o seu máximo vigor. Assim como ocorreu no teste de germinação, na primeira contagem à temperatura de $35^{\circ} \mathrm{C}$ em todos os substratos foi inadequada à germinação.

Cerne, Lavras, v. 17, n. 4, p. 525-531, out./dez. 2011 
Com base no teste de primeira contagem, os substratos vermiculita e papel favorecem ao processo de germinação de sementes de Stryphnodendron adstringens (Mart.) Coville (MARTINS et al., 2008a). O substrato papel toalha e a temperatura de $30^{\circ} \mathrm{C}$ apresentaram os maiores percentuais de germinação na primeira contagem de sementes de Cereus jamacaru DC. (GUEDES et al., 2009).

Os dados referentes ao índice de velocidade de germinação (IVG) de sementes de C. glaziovii submetidas a diferentes substratos e temperaturas estão na Tabela 3, onde se verifica que, mais uma vez, ocorreu interação significativa entre o substrato areia e a temperatura de $25^{\circ} \mathrm{C}$. Como ocorreu na porcentagem de germinação e na primeira contagem, os maiores índices de velocidade de germinação (fatores isolados) ocorreram na temperatura de $25^{\circ} \mathrm{C}$, em todos os substratos avaliados, seguidos da temperatura de $20-30^{\circ} \mathrm{C}$, também em todos os substratos. Entre os substratos destacam-se a areia e o papel tolha que expressaram maior velocidade de germinação nas temperaturas de 25,30 e $20-30^{\circ}$. No papel mata-borrão há menor velocidade de germinação das sementes, possivelmente, por uma menor área de contato entre substrato e semente que inviabilize a absorção rápida.

Tabela 3 - Índice de velocidade de germinação de sementes de Chorisia glaziovii (O. Kuntze) submetidas a diferentes substratos e temperaturas.

Table 3 - Seeds germination speed index of Chorisia glaziovii (O. Kuntze) subjected to different substrates and temperatures.

\begin{tabular}{lcccc}
\hline \multirow{2}{*}{ Substratos } & \multicolumn{4}{c}{ Temperaturas $\left({ }^{\circ} \mathrm{C}\right)$} \\
\cline { 2 - 5 } & 25 & 30 & 35 & $20-30$ \\
\hline Areia & $4,525 \mathrm{aA}$ & $2,795 \mathrm{aC}$ & $0,847 \mathrm{aD}$ & $3,184 \mathrm{aB}$ \\
Vermiculita & $2,513 \mathrm{cA}$ & $1,498 \mathrm{bC}$ & $0,505 \mathrm{bD}$ & $1,847 \mathrm{bB}$ \\
Sobre Papel & $2,061 \mathrm{dA}$ & $1,061 \mathrm{cB}$ & $0,000 \mathrm{cC}$ & $1,300 \mathrm{cB}$ \\
Papel Toalha & $3,958 \mathrm{bA}$ & $3,000 \mathrm{aC}$ & $0,025 \mathrm{aC}$ & $3,348 \mathrm{aB}$ \\
\hline
\end{tabular}

Médias seguidas de mesma letra minúscula na coluna e maiúscula na linha não diferem a 5\% de probabilidade pelo teste de Scott-Knott.

Os maiores índices de velocidade de germinação para sementes de Tabebuia serratifolia (Vahl) Nicholson, foram atingidos na temperatura de $15^{\circ} \mathrm{C}$ e o substrato areia (MACHADO et al., 2002); para Peltophorum dubium (Sprengel) Taubert $30^{\circ} \mathrm{C}$ e o substrato papel toalha (OLIVEIRA et al., 2008); nas sementes de Eucalyptus dunnii Maiden $30^{\circ} \mathrm{C}$ e o substrato areia (CETNARSKI FILHO; CARVALHO, 2009). Nas sementes de Amburana cearensis (Allemão) A.C. Smith $30,35^{\circ} \mathrm{C}$ e $20-30^{\circ} \mathrm{C}$ e substratos areia e vermiculita (GUEDES et al., 2010).
De modo similar ao que ocorreu nas variáveis anteriores, o desenvolvimento inicial das plântulas avaliado pelo comprimento da raiz e da parte aérea também foi afetado pelo uso dos diferentes substratos e temperaturas testados (Tabelas 4 e 5 ). No comprimento da raiz, houve interação da temperatura de $25^{\circ} \mathrm{C}$ com o substrato papel toalha. Já, para a parte aérea observa-se que houve interação entre a temperatura de $25^{\circ} \mathrm{C}$ e o substrato areia.

Tabela 4 - Comprimento da raiz (cm) de Chorisia glaziovii (O. Kuntze) oriundas de sementes submetidas a diferentes substratos e temperaturas.

Table 4 - Seedlings root length (cm) Chorisia glaziovii $(O$. Kuntze) derived from seeds subjected to different substrates and temperatures.

\begin{tabular}{lcccc}
\hline \multirow{2}{*}{ Substratos } & \multicolumn{4}{c}{ Temperaturas $\left({ }^{\circ} \mathrm{C}\right)$} \\
\cline { 2 - 5 } & 25 & 30 & 35 & $20-30$ \\
\hline Areia & $3,627 \mathrm{bA}$ & $3,182 \mathrm{aB}$ & $0 \mathrm{aC}$ & $3,245 \mathrm{bB}$ \\
Vermiculita & $3,199 \mathrm{cA}$ & $1,684 \mathrm{bB}$ & $0 \mathrm{aC}$ & $3,108 \mathrm{bA}$ \\
Sobre Papel & $1,331 \mathrm{dA}$ & $1,186 \mathrm{bA}$ & $0 \mathrm{aB}$ & $1,307 \mathrm{cA}$ \\
Papel Toalha & $4,105 \mathrm{aA}$ & $3,348 \mathrm{aB}$ & $0 \mathrm{aC}$ & $3,533 \mathrm{aB}$ \\
\hline
\end{tabular}

Médias seguidas de mesma letra minúscula na coluna e maiúscula na linha não diferem a 5\% de probabilidade pelo teste de Scott-Knott.

Tabela 5 - Comprimento da parte aérea $(\mathrm{cm})$ de Chorisia glaziovii (O. Kuntze) oriundas de sementes submetidas a diferentes substratos e temperaturas.

Table 5 - Length of aerial part (cm) Chorisia glaziovii $(O$. Kuntze) of seedlings derived from seeds subjected to different substrates and temperatures.

\begin{tabular}{lcccc}
\hline \multirow{2}{*}{ Substratos } & \multicolumn{4}{c}{ Temperaturas $\left({ }^{\circ} \mathrm{C}\right)$} \\
\cline { 2 - 5 } & 25 & 30 & 35 & $20-30$ \\
\hline Areia & $8,732 \mathrm{aA}$ & $8,215 \mathrm{aB}$ & $0 \mathrm{aC}$ & $8,421 \mathrm{aB}$ \\
Vermiculita & $6,994 \mathrm{bA}$ & $2,253 \mathrm{cC}$ & $0 \mathrm{aD}$ & $5,915 \mathrm{bB}$ \\
Sobre Papel & $1,792 \mathrm{dA}$ & $1,444 \mathrm{~dB}$ & $0 \mathrm{aC}$ & $1,513 \mathrm{cB}$ \\
Papel Toalha & $6,164 \mathrm{cA}$ & $5,370 \mathrm{bB}$ & $0 \mathrm{aC}$ & $5,885 \mathrm{bB}$ \\
\hline
\end{tabular}

Médias seguidas de mesma letra minúscula na coluna e maiúscula na linha não diferem a 5\% de probabilidade pelo teste de Scott-Knott.

Ao serem observados os fatores isolados constatouse que, mais uma vez, a temperatura de $25^{\circ} \mathrm{C}$ promoveu o maior vigor em todos os substratos estudados, com as maiores médias de comprimento de raiz e parte aérea. Nas Tabelas 4 e 5 , ainda verifica-se que na temperatura de $35^{\circ} \mathrm{C}$ não há registro de comprimento das partes das plântulas, uma vez que esta não permitiu o desenvolvimento

Cerne, Lavras, v. 17, n. 4, p. 525-531, out./dez. 2011 
adequado das plântulas, em razão do desenvolvimento dos fungos, os quais fizeram com que as plântulas tivessem sua raiz e caule apodrecidos.

O melhor desenvolvimento da raiz primária ocorreu nos substratos entre e sobre areia a $27^{\circ} \mathrm{C}$ e entre areia a $20-35^{\circ} \mathrm{C}$ para Myracrodruon urundeuva Fr. All., (PACHECO et al., 2006); No substrato papel toalha e à $30^{\circ} \mathrm{C}$ para Tabebuia aurea (Silva Manso) Benth. \& Hook F. ex S. Moore (PACHECO et al., 2008). No substrato vermiculita e a $30,35^{\circ} \mathrm{C}$ e $20-30^{\circ} \mathrm{C}$ para Amburana cearensis (Allemão) A.C. Smith (GUEDES et al., 2010). Já, para o desenvolvimento de parte aérea registraram-se os maiores comprimentos nas temperaturas de 20-30, 25 e $30^{\circ} \mathrm{C}$, independentemente do substrato (rolo de papel e sobre papel) para Adenanthera pavonina L. (KISSMANN et al., 2007); nos substratos papel, areia, pó de coco e tropstrato ${ }^{\circledR}$ à $35^{\circ} \mathrm{C}$ Tabebuia aurea (Silva Manso) Benth. $\&$ Hook F. ex S. Moore (PACHECO et al., 2008).

\section{CONCLUSÕES}

O teste de germinação das sementes de Chorisia glaziovii (O. Kuntze) deve ser conduzido na temperatura de $25^{\circ} \mathrm{C}$ ou $20-30^{\circ} \mathrm{C}$, com o substrato areia ou papel toalha.

A temperatura de $35^{\circ} \mathrm{C}$ não é recomendada para a germinação das sementes de C. glaziovii.

\section{REFERÊNCIAS}

ANDRADE, A. C. S.; PEREIRA, T. S.; FERNANDES, M. J.; CRUZ, A. P. M.; CARVALHO, A. S. R. Substrato, temperatura de germinação e desenvolvimento pós-seminal de sementes de Dalbergia nigra. Pesquisa Agropecuária Brasileira, Brasília, v. 41, n. 3, p. 517-523, mar. 2006.

BEWLEY, J. D.; BLACK, M. Seeds: physiology of development and germination. 2. ed. New York: Plenum, 1994. $445 \mathrm{p}$.

BEZERRA, A. M. E.; MOMENTÉ, V. G.; ARAÚJO, E. C.; MEDEIROS FILHO, S. Germinação e desenvolvimento de plântulas de melão-de-são-caetano em diferentes ambientes e substratos. Revista Ciência Agronômica, Fortaleza, v. 33, n. 1, p. 39-44, 2002.

CARNEIRO, J. W. P.; GUEDES, T. A. Influência do contato das sementes de Stevia (Stevia rebaudiana (Bert.) Bertoni), no substrato, avaliada pela função de Weibull.

Revista Brasileira de Sementes, Brasília, v. 14, n. 1, p. 6572, 1992.

Cerne, Lavras, v. 17, n. 4, p. 525-531, out./dez. 2011
CARVALHO, N. M.; NAKAGAWA, J. Sementes: ciência, tecnologia e produção. 4. ed. Jaboticabal: Funep, 2000. 588 p.

CETNARSKI FILHO, R.; CARVALHO, R. I. N. Massa da amostra, substrato e temperatura para teste de germinação de sementes de Eucalyptus dunnii Maiden. Ciência Florestal, Santa Maria, v. 19, n. 3, p. 257-265, 2009.

DOUSSEAU, S.; ALVARENGA, A. A.; ARANTES, L. O.; OLIVEIRA, D.; NERY, F. C. Germinação de sementes de tanchagem (Plantago tomentosa Lam.): influência da temperatura, luz e substrato. Ciência e Agrotecnologia, Lavras, v. 32, n. 2, p. 438-443, mar./abr. 2008.

FIGLIOLIA, M. B.; OLIVEIRA, E. C.; PIÑA-RODRIGUES, F. C. M. Análise de sementes. In: AGUIAR, I. B.; PIÑARODRIGUES, F. C. M.; FIGLIOLIA, M. B. (Coord.). Sementes florestais tropicais. Brasília: ABRATES, 1993. p. 137-174.

GODOI, S.; TAKAKI, M. Efeito da temperatura e a participação do fitocromo no controle da germinação de sementes de embaúba. Revista Brasileira de Sementes, Pelotas, v. 27, n. 2, p. 87-90, 2005.

GUEDES, R. S.; ALVES, E. U.; GONÇALVES, E. P.; BRAGA JÚNIOR, J. M.; VIANA, J. S.; COLARES, P. N. Q. Substratos e temperaturas para testes de germinação e vigor de sementes de Amburana cearensis (Allemão) A.C. Smith. Revista Árvore, Viçosa, v. 34, n. 1, p. 57-64, 2010.

GUEDES, R. S.; ALVES, E. U.; GONÇALVES, E. P.; BRUNO, R. L. A.; BRAGA JÚNIOR, J. M.; MEDEIROS, M. S. Germinação de sementes de Cereus jamacaru DC. em diferentes substratos e temperaturas. Acta Scientiarum. Biological Sciences, Londrina, v. 31, p. 159-164, 2009.

IOSSI, E.; SADER, R.; PIVETTA, K. F. L.; BARBOSA, J. C. Efeitos de substratos e temperaturas na germinação de sementes de tamareira-anã (Phoenix roebelenii O'Brien). Revista Brasileira de Sementes, Pelotas, v. 25, n. 2, p. 63-69, 2003.

KISSMANN, C.; SCALON, S. P. Q.; SCALON FILHO, H.; RIBEIRO, N. Tratamentos para quebra de dormência, temperaturas e substratos na germinação de Adenanthera pavonina L. Ciência e Agrotecnologia, Lavras, v. 32, n. 2, p. 668-674, 2007. 
LONE, A. B.; TAKAHASHI, L. S. A.; FARIA, R. T.; UNEMOTO, L. K. Germinação de Melocactus bahiensis (Cactaceae) em diferentes substratos e temperaturas. Scientia Agraria, Curitiba, v. 8, n. 4, p. 365-369, 2007.

LOPES, J. C.; CAPUCHO, M. T.; MARTINS FILHO, S.; REPOSSI, P. A. Influência de temperatura, substrato e luz na germinação de sementes de bertalha. Revista Brasileira de Sementes, Londrina, v. 27, n. 2, p. 18-24, 2005.

LORENZI, H. Árvores brasileiras: manual de identificação e cultivo de plantas arbóreas nativas do Brasil. 4. ed. Nova Odessa: Plantarium, 2002. v. 1, 367 p.

LUCENA, R. F. P.; NASCIMENTO, V. T.; ARAÚJO, E. L.; ALBUQUERQUE, U. P. Local uses of native plants in an area of caatinga vegetation (Pernambuco, NE Brazil). Ethnobotany Research and Applications, Honolulu, v. 6, p. 3-13, 2008.

MACHADO, C. F.; OLIVEIRA, J. A.; DAVIDE, A. C.; GUIMARÃES, R. M. Metodologia para a condução do teste de germinação em sementes de ipê-amarelo (Tabebuia serratifolia (Vahl) Nicholson). Cerne, Lavras, v. 8, n. 2, p. 17-25, 2002.

MAGUIRE, J. D. Speed of germination aid in selection and evaluation for seeding emergence and vigor. Crop Science, Madison, v. 2, n. 2, p. 76-177, 1962.

MARTINS, C. C.; MACHADO, C. G.; NAKAGAWA, J. Temperatura e substrato para o teste de germinação de sementes de barbatimão ((Stryphnodendron adstringens (Mart.) Coville (Leguminosae)). Revista Árvore, Viçosa, v. 32 , n. 4, p. 633-639, 2008a.

MARTINS, C. C.; MARTINELLI-SENEME, A.; NAKAGAWA, J. Estágio de colheita e substrato para o teste de germinação de sementes de ipê (Tabebuia chrysotricha (Mart. ex DC.) Standl.). Revista Árvore, Viçosa, v. 32, n. 1, p. 27-32, 2008b.

OLIVEIRA, L. M.; DAVIDE, A. C.; CARVALHO, M. L. M. Teste de germinação de sementes de Peltophorum dubium (Sprengel) Taubert - Fabaceae. Floresta, Curitiba, v. 38, n. 3, p. $545-551,2008$.
PACHECO, M. V.; MATOS, V. P.; FELICIANO, A. L. P.; FERREIRA, R. L. C. Germinação de sementes e crescimento inicial de plântulas de Tabebuia aurea (Silva Manso) Benth. \& Hook f. ex S. Moore. Ciência Florestal, Santa Maria, v. 18, n. 2, p. 143-150, 2008.

PACHECO, M. V.; MATOS, V. P.; FERREIRA, R. L. C.; FELICIANO, A. L. P.; PINTO, K. M. S. Efeito de temperaturas e substratos na germinação de sementes de Myracrodruon urundeuva Fr. All. (Anacardiaceae). Revista Árvore, Viçosa, v. 30, n. 3, p. 359-367, 2006.

PASSOS, M. A. A.; SILVA, F. J. B. C.; SILVA, E. C. A.; PESSOA, M. M. L.; SANTOS, R.C. Luz, substrato e temperatura na germinação de sementes de cedro-vermelho. Pesquisa Agropecuária Brasileira, Brasília, v. 43, n. 2, p. 281-284, fev. 2008.

PETERSON, J. R.; COOPER, P. G. Some considerations of water in the germination test. Seed Science and Technology, Zürich, v. 7, n. 3, p. 329-340, 1979.

PIVETTA, K. F. L.; SARZI, I.; ESTELLITA, M.; BECKMANN-CAVALCANTE, M. Z. Tamanho do diásporo, substrato e temperatura na germinação de sementes de Archontophoenix cunninghamii (Arecaceae). Revista de Biologia e Ciências da Terra, Campina Grande, v. 8, n. 1, p. 126-134, 2008.

SETUBAL, J. W.; AFONSO NETO, F. C. Efeito de substratos alternativos e tipos de bandejas na produção de mudas de pimentão. Horticultura Brasileira, Brasília, v. 18, p. 593594, 2000. Suplemento.

SOUZA, E. B.; PACHECO, M. V.; MATOS, V. P.; FERREIRA, R. L. C. Germinação de sementes de Adenanthera pavonina L. em função de diferentes temperaturas e substratos. Revista Árvore, Viçosa, v. 31, n. 3, p. 437-443, 2007.

STOCKMAN, A. L.; BRANCALION, P. H. S.; NOVEMBRE, A. D. L. C.; CHAMMA, H. M. C. P. Sementes de ipê-branco (Tabebuia roseo-alba (Ridl.) Sand. - Bignoniaceae): temperatura e substrato para o teste de germinação. Revista Brasileira de Sementes, Pelotas, v. 29, p. 139-143, 2007.

Cerne, Lavras, v. 17, n. 4, p. 525-531, out./dez. 2011 
